\title{
Proceeding
}

6th INSHS International Christmas Sport Scientific Conference, 11-14 December 2011. International Network of Sport and

Health Science. Szombathely, Hungary

\section{Neurofeedback course applying of high skilled gymnasts in competitive period}

\author{
OLGA STRIZHKOVA , LARISA CHERAPKINA, TATIANA STRIZHKOVA \\ Department of Anatomy, Physiology, Sport Medicine and Hygiene, Siberian State University of Physical Education \\ and Sport, Russia
}

\begin{abstract}
Strizhkova O,Cherapkina L, Strizhkova T. Neurofeedback course applying of high skilled gymnasts in competitive period. J. Hum. Sport Exerc. Vol. 7, No. Proc1, pp. S185-S193, 2012. Carried out researches with 28 high skilled gymnasts (15 - main group, 13 - control group) allowed to define the neurofeedback influence on functional condition of the sportswomen in competitive period. Neurofeedback course promotes improvement of rapidity of complex coordinating movements' memorization, vestibular stability and self-estimation of functional condition. Also it conducts to alpha-rhythm power increasing at left hemisphere. Neurofeedback course efficiency is defined by index of change of course average alpharhythm power with $100 \%$ prognostic accuracy. Attention switching, attention stability and self-estimation of sleep and memory are predictors of neurofeedback course successfulness. Key words: EFFICIENCY, SUCCESSFULNESS, CEREBRUM BIOELECTRIC ACTIVITY, PREDICTORS.
\end{abstract}

Corresponding author. 644010 , fl. 148, b. 15, s. Maslennikova, c. Omsk, Russia.

E-mail: strishi85@mail.ru

6th INSHS International Christmas Sport Scientific Conference, 11-14 December 2011. International Network of Sport and Health Science. Szombathely, Hungary

JOURNAL OF HUMAN SPORT \& EXERCISE ISSN 1988-5202

(C) Faculty of Education. University of Alicante

doi:10.4100/jhse.2012.7.Proc1.21 


\section{INTRODUCTION}

The competitive period it's a stage of realization of sportsmen's cumulate potential (Smolevsky, 1999). Therefore applying of methodologies which allow optimizing sportsmen's functional condition before competition acquires special importance (Shamardin, 2009). According to literary data the peak performance achievement by high skilled sportsmen is accompanied by alpha-activity increasing (Bazanova, 2009). Pre-starting state is optimized and recovery processes efficiency increases if alphaactivity grow (Bazarin, 2009). In this connection the applying of neurofeedback course, directional on alpharhythm power increasing is especially urgent in sport practice (Tristan et al., 2008).

At present there is a number of researches devoted to study of neurofeedback influencing on condition of the different specialization sportsmen (Geraschenko, 2002; Shandibina, 2008; Tristan et al., 2008). The attempts of studying of neurofeedback applying regularities in sport were being taken. In particular predictors of alpha-training efficiency were being studied (Pogadaeva, 2001). But previously researches did not take into account the sport specialization. From that it should be that specific effects of neurofeedback applying are not studied enough. In addition neurofeedback role in training process of high skilled sportswomen is not clear. The regularities of neurofeedback influencing on sportswomen during competitive period are not defined. Thereby the purpose of this research is the revealing of neurofeedback influencing features on sportswomen-gymnasts in the competitive period.

\section{MATERIAL AND METHODS}

In present research 28 high skilled sportswomen practicing sport types of gymnastics took a part. 15 sportswomen made up the main group, and 13 - the control group. Neurofeedback course, directional on alpha-rhythm power increasing was held out in the main group with using software-hardware package "Boslab-alpha" (SRIMBB SB RAMS c. Novosibirsk). Bipolar disposal was used for recording of cerebrum biopotentials. Electrodes were located according to international system "10-12" at the frontal and parietal fields (F1, F2, P3, P4). Neurofeedback course consisted of 15 sessions. Sessions were held 1time per day before workout. At each session of the alpha-training sportswomen were receiving the information about session successfulness and were able to estimate their abilities to cerebrum bioelectric activity selfregulation (Pogadaeva et al., 2001). 
Before and after neurofeedback course the complex examination of sportswomen was carried out and included: recording of "background" cerebrum bioelectric activity in a state of opened and closed eyes with following analysis of spectral power in frequency bands theta $(4-8 \mathrm{~Hz})$, alpha $(8-13 \mathrm{~Hz})$, beta-activity $(13-20$ $\mathrm{Hz}$ ); recording of electrocardiogram in the second standard disposal with following analysis of heart rate variability indexes by Baevsky's (1997) methodology; survey with using of questionnaire "Self-estimation of functional condition and training level" (Pogadaeva, 2002); estimation of reactive and personal anxiety by Spilberger-Khanin scale; assessment of psychological tension level (Wallnofer's coefficient) on the base of 8 colors Lusher test (Sobchik, 2007); test truncated pyramid (Maklakov, 2001); Romberg's test (Grigor'ev et al., 2010); test for revealing of rapidity of complex coordinating movements memorization (Strizhkova et al., 2005); estimation of time of competitive program ideomotor execution (Pikkenhein, 1980) and of the time of competitive program execution by upper extremities (Strizhkova et al., 2005).

Training successfulness was assessed by Svyatogor's et al. (2000) methodology and was amounted in percentage ratio of successful sessions to common number of held sessions.

Pre-training indexes of functional condition were compared with equal post-training indexes to determine training efficiency. Neurofeedback course was considered effective if more than $30 \%$ of indexes indicated about improvement of functional condition. In case when less than $30 \%$ indexes were improved training was considered noneffective.

Statistical treatment was held with program SPSS 13.0 for Windows (Nasledov, 2009). Normalcy of distribution was estimated by skewness and kurtosis criterions.

\section{RESULTS}

Registration of "background" electroencephalogram allowed to reveal that in a state of opened eyes, sportswomen in control group (the initial index was $2.74 \pm 0.08 \mathrm{mcV} 2 \times \mathrm{s}$, the repeated $-3.32 \pm 0.16 \mathrm{mcV} 2 \times \mathrm{s}$ ) as well as sportswomen in the main group (pre-training index was $-2.95 \pm 0.14 \mathrm{mcV} 2 \times \mathrm{s}$, post-training $3.59 \pm 0.23 \mathrm{mcV} 2 \times \mathrm{s}$ ) had increasing $(p<0.05)$ of left hemisphere alpha-rhythm power (Figure 1). In a state of closed eyes the increasing of alpha-rhythm spectral power took place only in the main group (pre-training index was $-3.06 \pm 0.18 \mathrm{mcV} 2 \times s$, post-training $-4.27 \pm 0.35 \mathrm{mcV} 2 \times \mathrm{s})(\phi<0$. 05). The power of studied rhythms at right hemisphere did not change during competitive period $(p>0.05)$. 


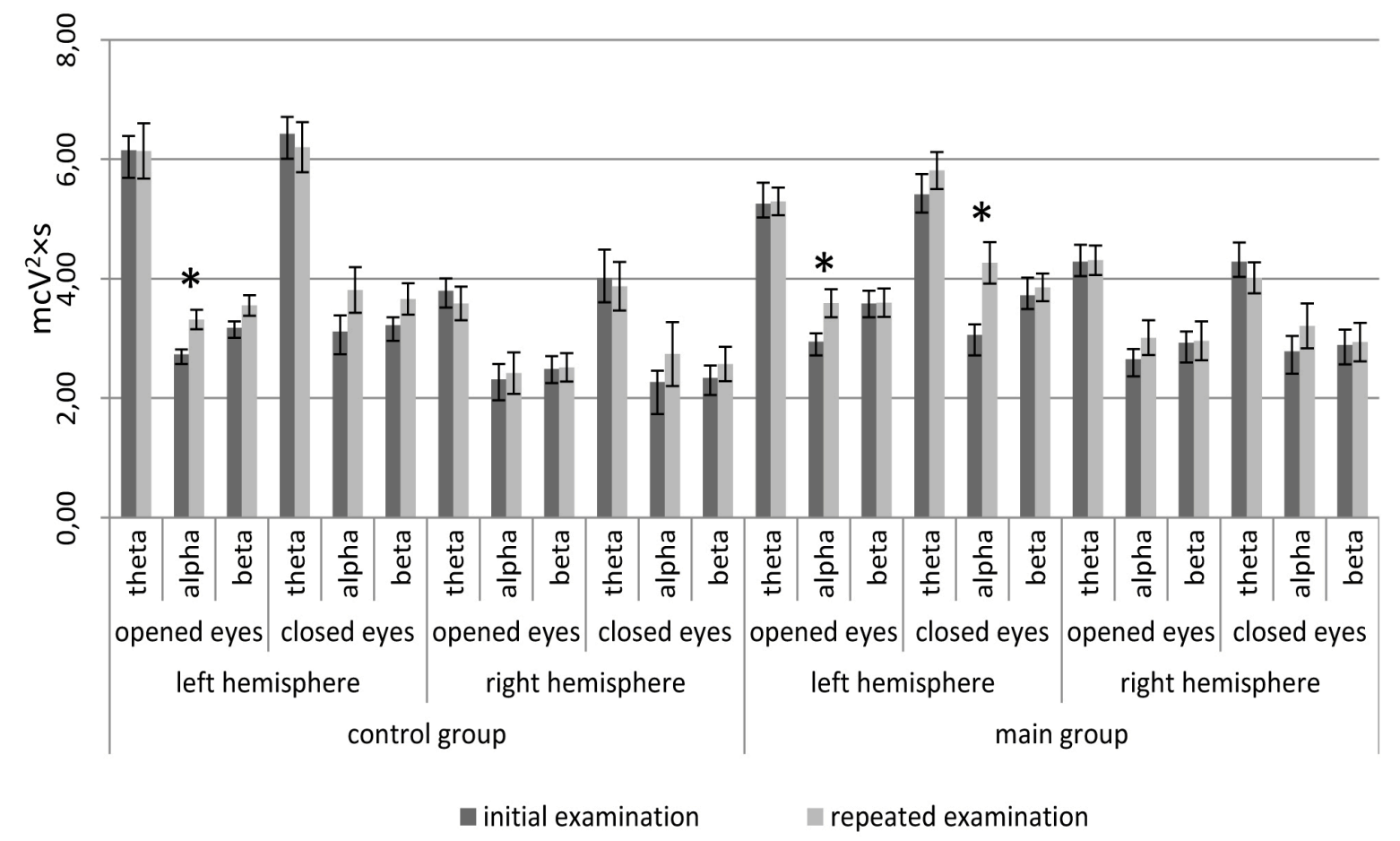

Figure 1. "Background" cerebrum bioelectric activity of gymnasts-women in main and control groups, $M \pm m ;{ }^{*}$ - differences between initial and repeated indexes with $p<0,05$

Neurofeedback course average index of alpha-rhythm power at left hemisphere $(3.65 \pm 0.21 \mathrm{mcV} 2 \times \mathrm{s})$ was higher than alpha-rhythm power at the same hemisphere, registered in the pre-training "background" electroencephalogram $(3.06 \pm 0.18 \mathrm{mcV} 2 \times s)(p<0.05)$. Course average indexes of spectral EEG power in theta- and beta-band did not differ from equal initial indexes. Successfulness of neurofeedback course, held in competitive period was $40 \%$. This mean corresponded to middle level according to Svyatogor's et al. (2000) classification.

During assessment of complex coordinated activity in competitive period it was revealed that after neurofeedback course applying sportswomen in the main group differed from control group by more exact time of ideomotor execution of competitive program $(p<0.05)$ (Table 1). In main group the time of complex coordinating motions learning decreased $(p<0.05)$ and vestibular stability improved $(p<0.05)$ after neurofeedback using in the competitive period. In control group this indexes didn't change. 
Table 1. Indexes of complex coordinated activity of gymnasts-women in main and control

\begin{tabular}{|c|c|c|c|c|c|c|c|c|c|c|c|c|}
\hline \multirow{3}{*}{ Group } & \multicolumn{12}{|c|}{ Indexes } \\
\hline & \multicolumn{3}{|c|}{ Romberg's test(s) } & \multicolumn{3}{|c|}{$\begin{array}{l}\text { Rapidity of complex } \\
\text { coordinating movements } \\
\text { memorization(s) }\end{array}$} & \multicolumn{3}{|c|}{$\begin{array}{l}\text { Ideomotor execution of } \\
\text { competitive program (\%) }\end{array}$} & \multicolumn{3}{|c|}{$\begin{array}{l}\text { Execution of competitive } \\
\text { program by upper } \\
\text { extremities }(\%)\end{array}$} \\
\hline & I & II & $\mathrm{p}_{\mathrm{HI}}$ & $\mathrm{I}$ & II & $\mathrm{p}_{\mathrm{HI}}$ & I & II & $\mathrm{p}_{\mathrm{HI}}$ & $\mathrm{I}$ & II & $\mathrm{p}_{\mathrm{HI}}$ \\
\hline $1(n=13)$ & $16 \pm 3,4$ & $19 \pm 5,5$ & - & $80 \pm 20$ & $104 \pm 14,6$ & - & $87 \pm 5,5$ & \multirow{2}{*}{$\begin{array}{c}87 \pm 4,7 \\
p_{1-2}<0,05 \\
97 \pm 2,0\end{array}$} & - & $88 \pm 3,3$ & $90 \pm 3,8$ & - \\
\hline $2(\mathrm{n}=15)$ & $14 \pm 2,8$ & $30 \pm 6,5$ & * & $93 \pm 7,2$ & $78 \pm 7,8$ & * & $95 \pm 3,9$ & & - & $93 \pm 2,6$ & $98 \pm 3,4$ & - \\
\hline
\end{tabular}

The holding of training in this period significantly influenced on sportswomen's self-estimation of functional condition $(p<0.05)$ (Figure 2). In main group sportswomen noted the improvement of their condition by 11 indexes from 15. Particularly after neurofeedback holding sportswomen higher than before training estimated their self-feeling (before - 2.4 points, after -3.4 points) $(p<0.01)$, mood (before -3.4 points, after -3.9 points) ( $p<0.05)$, desire for communication with another people (before -3.3 points, after -3.6 points) $(p<0.05)$, memory (before -2.9 points, after -3.4 points) ( $p<0.01$ ), attention (before -2.9 points, after -3.4 points) ( $p<0.01$ ), self-reliance (before -3.2 points, after -3.8 points) $(p<0.01)$, capacity for work during workouts (before -3.4 points, after -3.9 points) ( $p<0.05$ ), analysis of technique and hold during workout (before -3.3 points, after -3.8 points) $(p<0.05)$, tactical thinking (before -3.4 points, after -3.8 points) $(p<0.05)$, emotional condition control during workout (before -3.2 points, after -3.6 points) $(p<0.01)$ and desire for creation (before -2.8 points, after -3.7 points) $(p<0.01$ ). In control group sportswomen estimated their repeated indexes of functional condition the same as initial. 


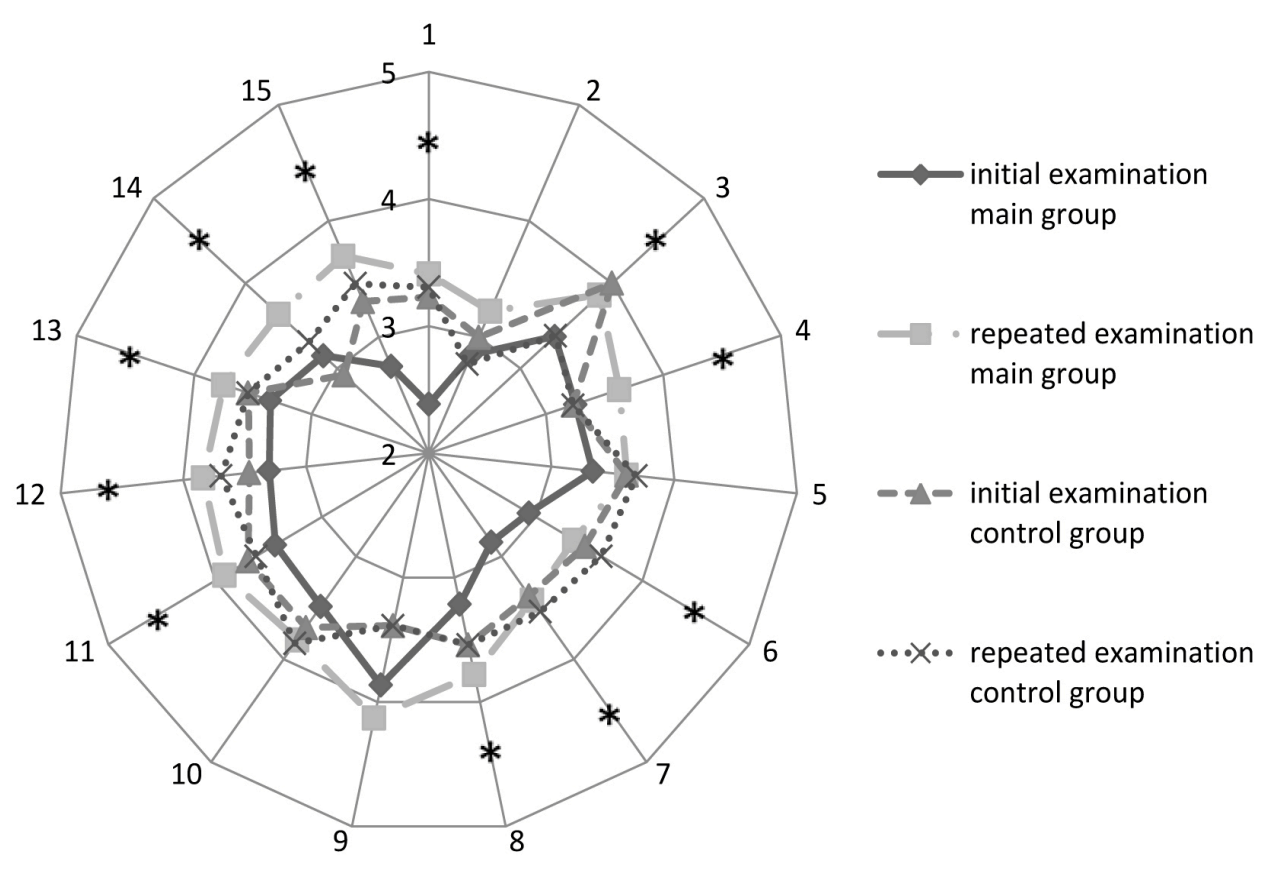

Figure 2. Indexes of functional condition self-estimation of gymnasts-women in main and control groups (points)

The indexes: 1 -self-feeling, 2 -activity, 3 -mood, 4 -desire for communication with another people, 5 -sleep, 6 - memory, 7 -attention, 8 - self-reliance, 9 -academic results, 10 - selfestimation of occupation and behaviour, 11 -capacity for work during workouts, 12 -analysis of technique and hold during workout, 13 - technical thinking, 14 - emotional condition control during workout, 15 - desire for creation. * - differences between initial and repeated indexes in main group with $p<0,05$.

In the competitive period neurofeedback course did not influence on attention stability and attention switching, on indexes of personal and reactive anxiety, on Wallnofer's coefficient and on the cardiointervalographic indexes of high skilled sportswomen $(p>0.05)$. In control group these indexes didn't change also.

The holding of regression analysis allowed determining that in the competitive period the predictors of neurofeedback successfulness were attention switching (ASw) (positive connection) and attention stability (ASt) (negative connection) (Table 2). The predictors of alpha-rhythm power increasing were indexes of self-estimation of sleep (SS) (negative connection) and of memory (SM) (positive connection). The equations of regression were:

Table 2

\begin{tabular}{|c|}
\hline$\%$ of successful sessions $=-11.07+8.03^{*} \mathrm{ASw}-1.53^{*} \mathrm{ASt} ;$ \\
\hline Increasing of alpha-rhythm power $=4.33-0.80^{*} \mathrm{SS}+0.59^{*} \mathrm{SM}$. \\
\hline
\end{tabular}


According to results of discriminant analysis initial indexes of "background" cerebrum bioelectric activity of gymnasts did not define neurofeedback course efficiency in competitive period. At the same time in this period the index of alpha-rhythm power course average change was the predictor of the training efficiency. The equation of discriminant function looked as:

$$
d=1.410^{*} \Delta a-0.319
$$

It indicated that, when alpha (a) get higher, then training efficiency rise. The means of discriminator differed significantly $(p<0.001)$ and were -4.324 - for noneffective training and 0.333 - for effective training. The canonical correlation coefficient equaled to 0.79 and prognostic accuracy was $100 \%$.

\section{DISCUSSION}

The held researches allowed revealing that during the competitive period the increasing of left hemisphere alpha-rhythm power was distinctive for high skilled sportswomen-gymnasts, but it was more significant if neurofeedback course was holding in this period. By the Bazarin's et al. (2009) data, the alpha-state is the condition of "winner" and it is typical for high skilled sportsmen. Author connects the appearing of this condition after alpha-stimulated training with involvement of mechanisms of beta-endorphin - D2 dophamine receptors. Malikh (1997) revealed the high level of EEG determination at condition with closed eyes. Obviously by this reason EEG power in alpha-band with closed eyes increased only in the group where the neurofeedback course was held. These changes of cerebrum bioelectric activity of main group gymnasts were combined with improvement of certain indexes of complex coordinated activity. It indicates to improvement of central nervous system condition of gymnasts (Strelets \& Gorelov, 1996).

After neurofeedback course the significant increasing of functional condition self-estimation took place. By Shandibina's (2008) opinion, during workout it allows to sportsmen maintain "clarity" of thinking and improve the tactical thinking.

According to literary data, the decreasing of psychological tension coefficient (Tikhomirova, 2005) and reactive anxiety (Gubkina et al., 2007; Shandibina et al., 2008) is regular during neurofeedback using and is more significant when performance activity is lower. At the same time sportsmen, performing more active are characterized by tendency to increasing of these indexes (Zaytseva, 2001). But according to received data after neurofeedback applying in competitive period, reactive anxiety and psychological tension remain initial means. Also electroencephalographic biofeedback holding in this period did not influence on the personal anxiety level that agreed with Gubkina's et al. (2007) data.

\section{CONCLUSIONS}

Thereby, the results of this research showed that with the middle level of successfulness the neurofeedback course promotes the left hemisphere alpha-rhythm power increasing, which is accompanied by improvement of the complex coordinated activity and of functional condition self-estimation of gymnasts. The indexes of attention stability and switching as well as self-estimation of sleep and memory were predictors of neurofeedback successfulness. In the competitive period the efficiency of neurofeedback was defined by index of alpha-rhythm course average change with high prognostic accuracy (100\%). 


\section{REFERENCES}

1. BAEVSKY R, BERSENIOVA A. The assessment of organism adaptation abilities and risks of illness development; 1997.

2. BAZANOVA O. The psychophysiological signs of sensomotor integration. The influence of biological factors age, sex and neurohumoral status. Omsk: IX All-Russian scientific conference of Biofeedback in medicine and sport. 2009; 40-50.

3. BAZARIN K. The interaction of d2-dopamine receptors activation and the increasing of power EEG indexes in alpha-band. Omsk: IX All-Russian scientific conference of Biofeedback in medicine and sport. 2009; 65-67.

4. GERASCHENKO V, POGADAEVA O, TRISTAN V. Certain pedagogical effects of local alphastimulating training influence on the wu shu sportsmen. Omsk: IV All-Russian scientific conference of Biofeedback in medicine and sport. 2002; 45-48.

5. GRIGOR'EV A, ORLOV V, FITISOV O. Pre-nosological control and strengthening of somatic health and body functional reserves (medical technology "Health navigator"); 2010.

6. GUBKINA D, MADYAR S, KOVALEVSKAYA E, PAVLENKO V, BELALOV V, KELIP A, KRAVCHENKO E. Neuro- and psychophysiological effects of EEG feedback single session. Scientific notes of Tauride national university of V.I.Vernadskogo's name. 2007; 4(20):30-33.

7. MAKLAKOV A. General psychology. Teaching aid; 2001.

8. MALIKH S. The research of genetic determination of human EEG. Questions of psychology. 2008; 6:109-128.

9. NASLEDOV A. SPSS 15: Professional statistical analysis of data; 2009.

10. PIKKENHEIN L. The neurophysiological mechanisms of ideomotor training. The questions of psychology. 1980; 3:116-120.

11. POGADAEVA O, TRISTAN V. The human notion about time after AST. Omsk: III All-Russian scientific conference of Biofeedback in medicine and sport. 2001; 48-49.

12. POGADAEVA 0 . The predictors of efficiency of the alpha-stimulating training using in sport: author's abstract of Dis. Cand. Biol. Scien. Tomsk; 2001.

13. POGADAEVA O, CHERAPKINA L, BAIOVA N, KAL'SINA V, TRISTAN VV. The assessment of clinical efficiency of local alpha-stimulating training. Omsk: IV All-Russian scientific conference of Biofeedback in medicine and sport. 2002; 71-74.

14. SHAMARDIN A. The designation functional training of young footballer: author's abstract of Dis.Doc. Pedag. Scien. Sankt-Petersburg; 2009.

15. SHANDIBINA V. The cerebral mechanisms of sportsmen functional condition changes after local alpha-stimulating training. Omsk: VIII All-Russian scientific conference of Biofeedback in medicine and sport. 2008; 152-158.

16. SMOLEVSKY V. Sport gymnastic. Teaching aid; 1999.

17. SOBCHIK L. The method color choice. The modification of 8-color test; 2007.

18. STRELETS V, GORELOV A. The theory and practice of human vestibular-motor regulation in sport and professional occupation. Theory and practice of physical culture. 1996; 5:13-16.

19. STRIZHKOVA T, CHERAPKINA L, STRIZHKOVA O. The OMC phases influence on the EEG-FB training efficiency of sportswomen practiced in sport aerobic. Moscow: VII All-Russian scientific conference of Biofeedback in medicine and sport. 2005; 70-73.

20. SVYATOGOR I. The method of cerebrum potential biofeedback and clinical using of it. Biological. 2000; 1:5-7.

21. TIKHOMIROVA E, TICHINSKAYA M. The neurofeedback influence on fencers sport readiness. Moscow: VII All-Russian scientific conference of Biofeedback in medicine and sport. 2005; 81-83. 
22. TRISTAN V. SHANDIBINA V. The forming of phenomenon of sportsmen optimal functioning with the neurofeedback using. Novosibirsk: scientific conference of Biofeedback: new possibilities. 2008; 47-48.

23. ZAYTSEVA V. The anxiety changes under AST influence of male and female practiced in sport dances. Omsk: III All-Russian scientific conference of Biofeedback in medicine and sport. 2001; 41-43. 